\title{
Considerations on Blood Platelets: A Neuron's Mirror for Mood Disorders?
}

\author{
Massimo Cocchi ${ }^{12^{*}}$, Lucio Tonello ${ }^{1}$, Fabio Gabrielli ${ }^{1}$ \\ ${ }^{1}$ Paolo Sotgiu Institute for Research in Quantitative \& Quantum Psychiatry \& Cardiology, LU de S University, Lugano, Switzerland; \\ ${ }^{2}$ Department of Medical Veterinary Sciences, University of Bologna, Bologna, Italy. \\ Email: ${ }^{*}$ massimo.cocchi@unibo.it
}

Received March $7^{\text {th }}, 2012$; revised April 12 ${ }^{\text {th }}, 2012$; accepted April 25 $5^{\text {th }}, 2012$

\begin{abstract}
This work aims to be a reflection concerning a remarkable similarity between platelet and neuron. Through a series of experimental tests which have affected the fatty acid composition of the membrane of platelets, it was possible to provide a contribution to the scientific literature, which had already reported strong similarities between platelet and neuron. The work performed could be of great interest to investigate, by studying the interactome of the platelet, the molecular behavior of the neuron.
\end{abstract}

Keywords: Blood Platelets; Fatty Acids; Membrane Viscosity

\section{Introduction}

Platelets, which are considered cells with high affinity to neurons, have the same embryonic origin of brain and skin (ectoderma) [1-4]. This affinity, primarily, is related to aspects of serotonin modulation in different psychiatric disorders, particularly Major Depression (MD) and Bipolar Disorder (BD). Over the last thirty years, numerous and influential works have reported a similarity between platelet and neuron's serotonin concentration, mainly in $\mathrm{MD}$ and $\mathrm{BD}$ [5-13]. It is well known that reliance on symptom-based methods of diagnosis has limitations with respect to diagnostic accuracy [14] and is a rate-limiting step in terms of developing new effective treatments for these disorders [15]. Despite this evidence, it has not been given a relevant meaning to these scientific observations and the reason, probably, concerns the possibility of using just serotonin as a marker for the diagnosis.

\section{Platelet and Fatty Acid Profile}

There is substantial evidence to suggest that profiling the fatty acid content of platelets and evaluating their membrane viscosity may offer hitherto untapped potential in terms of diagnostic discriminatory capacity among various neuropsychiatric disorders.

Previous reports have suggested that the physical properties of cell membranes and calcium homeostasis in both the central and peripheral nervous systems are significantly altered in dementia [16].

\footnotetext{
"Corresponding author.
}

Comparing platelet membrane fluidity in patients with Alzheimer type dementia, the fluidity of the hydrocarbon region of platelet membranes from the demented group, as reflected by the steady-state anisotropy of the fluorescent probe 1,6-diphenyl-1,3,5-hexatriene (DPH), was significantly greater than that of the depressed and normal control subjects. Within the demented group, platelet membrane fluidity was significantly correlated with severity of dementia but not with duration of illness or age at onset. Demented patients with increased platelet membrane fluidity had an earlier onset, were more severely demented, and deteriorated more rapidly [17]. Furthermore, recent studies have shown that platelet amyloidal precursor protein levels are correlated with changes in membrane fluidity and cognitive decline in Alzheimer's disease [18].

The fluidity of cell membranes is determined in part by the relative composition of saturated versus unsaturated fatty acids within the membrane lipid bilayer; the higher the percentage of unsaturated fatty acids, the higher the fluidity of the membrane. Techniques have been also developed to characterize the relative compositions of membrane fatty acids in order to classify different populations of microbes using artificial neural network (ANN) approaches $[19,20]$.

ANNs provide a useful tool to recognize patterns in complex, nonlinear data sets such as those associated with fatty acid profiles. A particular form of ANN, that utilises unsupervised learning, for modelling biological data of this nature, is the Self Organising Map-SOM [21]. 
This approach has also been used in humans, to study the dynamic changes in fatty acid metabolism in cardiovascular disease [22-24].

Recent studies have demonstrated the existence of different viscosity levels of the membrane between subjects with Major Depression and apparently normal controls using this technique $[25,26]$. These studies, strongly suggest that running the fatty acid profile of platelets could be extremely useful in identifying specific biomarkers for those at risk of mood disorders and in addressing the treatment more correctly.

\section{Platelet Membrane Viscosity and Serotonin}

Recently, after about 30 years, it has been possible to demonstrate, with a mathematical model for the classifycation of the mood disorder, that platelet membrane viscosity regulates the depressive disorder and finds in Arachidonic Acid the main element of criticality when it is too high in platelets [26].

The aspect of neuron and platelet cell membrane viscosity [27] is often missed, as responsible of the central government of that bio molecular intracellular complex, called interactoma, and that is defined "as the whole array of molecular interactions that take place in an organism and allow the cascade of regulatory molecules including the mechanism of action of enzymes and metabolic reactions".

These findings agree with Heron [28] who described the correlation between serotonergic cell membrane viscosity and serotonin receptor binding capacity, and Lee [29] who reviews and discuss the role of lipids and cholesterol on neuron membrane viscosity and serotonin receptors. Research, anyway, didn't explain the link brain-platelet-serotonin. After 30 years it has been possible to demonstrate, with a mathematical model for the classification of the depressive disorder, that platelet membrane viscosity rhythms the depressive disorder and finds in Arachidonic Acid the main element of criticality when it is too high in platelets.

The high concentration of Arachidonic Acid in platelets is a step limit to its mutual exchange with the brain and, as a result, the Arachidonic acid increases its neuronal concentration, since brain receives Arachidonic Acid also from other sources [30,31].

Increased phospholipids arachidonic acid concentrations have been found both in the brain and plasma of depressed rats and humans [32,33].

This evidence, obtained from experimental data, and the construction of an appropriate mathematical model, would provide a further more concrete evidence of the similarity between platelet and neuron.

Therefore, three essential points constitute the issue about the relationship between the cytoskeleton molecular structure and the psychiatric disorder:

1) Serotonin levels

2) Platelet and neuron membrane viscosity

3) The Interactome-Consciousness relationship

On this matter and on the relationships between membrane viscosity and interactome, in relation to mood disorders and consciousness, a series of papers has been published [34-39].

\section{From Platelet Fatty Acid Profile to the Differential Diagnosis between MD and Bipolarism}

We report the sequence, in its essentials, of the path that led to the diagnosis of Mood Disorder, able to distinguish MD from bipolar disorder.

The first step provides for the analytical execution of platelet fatty acids in two groups of subjects.

There have been assessed, according to this approach, the membrane platelet fatty acids of two different groups: 1) 84 subjects (51 female and 33 males, average age: 60.21 , SD: \pm 12.27 ) with clinical diagnosis of Major Depression (tools used: Clinical Global Impression (CGI), Symptoms Check List-90 (SCL-90), Medical and Pharmacological history, BMI, Structured Clinical Interview DSM-IV-SCID-IV (American Psychiatric Association 2000), Hamilton Rating Scale of Depression (HRSD). The severity of the depressive symptoms has been evaluated through the Hamilton Rating Scale of Depression 21 items version (HRSD-21). 60 subjects (38 males and 22 females, average age: $33.97, \mathrm{SD}: \pm 12.40)$, apparently in healthy conditions, without a known history of MD. The investigation was authorized by the Ethic Committee of the Health Authorities.

Patients and controls were enrolled without taking into account age, gender, food behaviour and therapy. The direct task of finding bio-markers according to the rules given by the Evidence Based Medicine (EBM), requires the elimination of selection bias, and leads to a selectiveity of a population often not likely, almost unreal and usually clinically unrealistic.

The results concerning the fatty acids platelet, subsequently processed with a complex mathematical function (ANN-Self Organizing Map) have provided a selection of such fatty acids, namely:

Palmitic Acid, Linoleic Acid and Arachidonic Acid.

The response of the SOM was in the Figure 1.

We, afterwards, identified that the fatty acid combination, chosen by the SOM, represented a balance between saturated and unsaturated fatty acids.

To better understand the distribution of the subjects we tried to obtain a single number (B2 index) from the fatty acids triplet that could give evidence of the indirect degree of saturation/instauration of each case, we have utilized the following formula: 

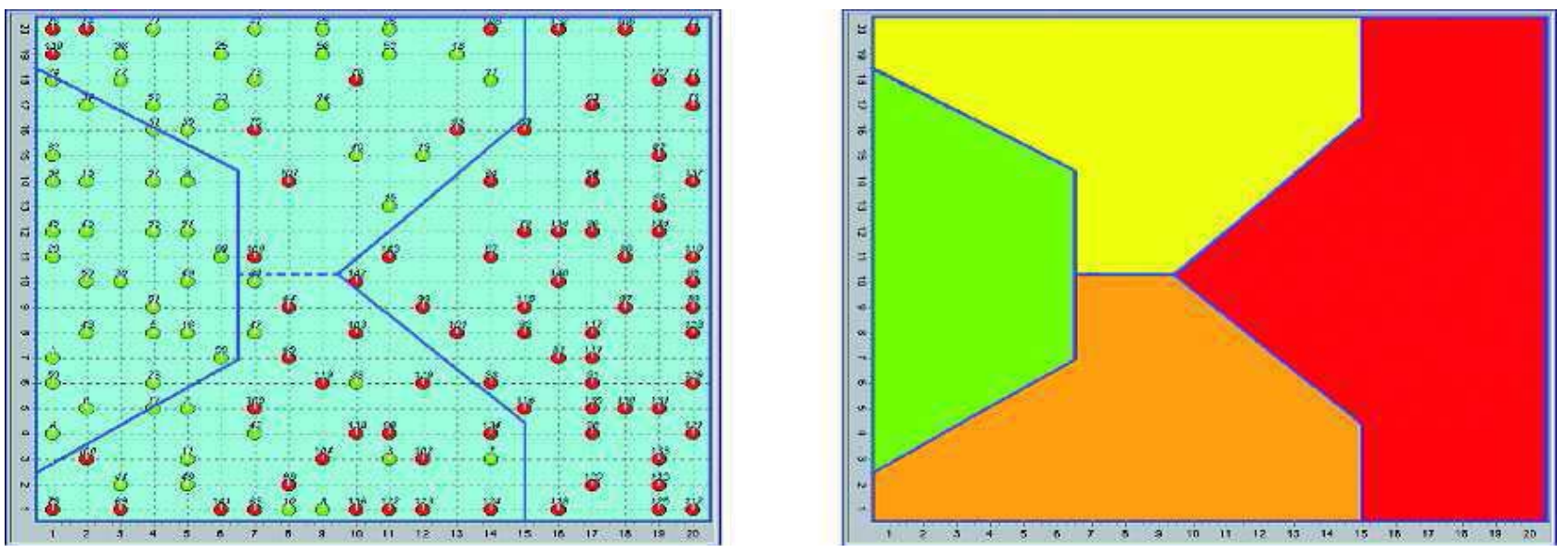

Figure 1. Distribution of subjects (normal-green and depressed-red) on the SOM (two-dimensional map), and SOM areas.

$$
B_{2}=\sum_{i=3}^{3}\left(A_{i} \frac{m p_{i}}{m w_{i}}\right)
$$

where: $A_{i}=$ per cent of $i$ Fatty Acid

$m w_{i}=$ molecular weight of $i$ Fatty Acid

$m p_{i}=$ melting point of $i$ Fatty Acid

The index of each subject (called B2) distributed on a one-dimensional map gave the following result (Figure 2).

This approach has enabled us to identify the index of each subject and the indirect measurement of the viscosity of the membrane, and how the distribution of the index reflects; it was shown that within the population diagnosed with mood disorders a further classification was possible between the negative and positive index.

At the time of research, since the final diagnosis that was given to us did not clarify the classification between the two types of disorder (MD and BD), but was limited simply to distinguish the mood disorders from apparently normal individuals [26], we decided to repeat the experiment (M. Cocchi, F. Canestrari, A. Mastrogiacomo, R. Silvestri, R. Venanzini, data not published) clarifying that the negative sign meets the diagnostic criteria for $\mathrm{MD}$ and the positive sign for BD (Figure 3).

\section{How Can We Read the Results Provided by Platelets?}

In addition to humans, many assumptions and experiments on animals were made, trying to understand whether what was written in platelet fatty acids was unequivocal or not.

To support the critical nature of this index we report the synthetic sequence of events that have convinced us of its unequivocal predestination.

The combination of the two independent mathematical models, a complex one (SOM) and a linear one (B2 index) is used to classify subjects, be they humans or animals,

with respect to the accurate diagnostic evidence (man) and to the behavior (animal).

Neither of the two mathematical models, taken separately, is exhaustive since it is from their combination that is possible to identify whether the subject, with the same index, belongs to the pathological area or not $[40$, 41].

This evidence led to a reflection, i.e., two subjects with the same index can have a different location over the map, i.e. one in normal position and one in pathologic position. In this case, in our opinion, the critical concentration of one or more fatty acids becomes crucial with respect to its involvement in cellular dynamics, which, to date, is not known and interpreted clearly.

Certainly, the involvement of the delta 6 desaturase activity seems plausible since the left side of the map recognizes high levels of linoleic acid and low levels of arachidonic acid, the opposite of the right side of the map.

Two factors justify and support this observation:

1) The amount of arachidonic acid, from food, has no significant effects on the level of the same fatty acid in cell membranes and in particular in platelets [42].

2) The evidence of the placement on the left side of the map of long-lived animals, for which it has been suggested a reduced activity of delta 6 desaturase as a condition of protection from the consequences of excessive production of arachidonic acid or, the same, for animals (feline) in which it is recognized an almost total deficiency of the enzyme [43].

A further confirmation of the above observations should come from the animals that are located in the pathological area (pig, rat and guinea pig), which, as shown in the table, have low levels of linoleic acid and high of arachidonic acid, with a B2 positive index; this would exclude the MD in the animal world (so far investigated) in favor of a biochemical characterization of the bipolar condition. 


\begin{tabular}{|c|c|c|c|c|c|c|c|c|c|c|c|c|c|c|c|c|c|c|c|c|}
\hline 20 & 24 & 17 & 1,92 & 89 & 1,92 & ,04 & 11 & 1,85 & 1,68 & 1,59 & 1,58 & 1,56 & 1,64 & 1,60 & 1,30 & 99 &, 50 & 0,02 & $-0,49$ & -10 \\
\hline 19 & 92 & 94 & 25 & & 1,98 & 98 & & 1,71 & 53 & 44 & ,37 & 1,53 & 1,70 &, 54 & 32 & & 48 & & 0,12 & 0 \\
\hline 18 & 34 & 28 & 21 & 20 & 11 & & 91 & 1,83 &, 55 & 34 & 36 & & 1,51 & & 29 & &, 39 & & 0,35 & 0,44 \\
\hline 17 & 36 & 37 & 27 & 19 & 22 & & 04 & 1,85 & & 55 & 39 & 32 & 31 & 30 & 23 & &, 39 &, 8 &, 43 &, 51 \\
\hline 16 & 03 & 57 & 35 & & & & & & & & & & & & & & 0,40 & 43 & 0,46 & 0,47 \\
\hline 15 & 3,21 & 19 &, 59 & 2,47 & 2,53 & 9 & 2,21 & 2,41 & 1,67 & 40 & 1,27 & 1,14 & 1,22 & 1,21 & 1,22 &, 72 & 0,53 & 0,47 & 0,47 & 0,15 \\
\hline 14 & 13 & 24 & 76 &, 55 & 2,79 & 73 & 55 & 2,57 & 27 & 36 & ,15 & 1,13 & 1,16 & 1,16 & 1,08 &, 55 & 0,54 & 0,48 & 0,11 & $-0,49$ \\
\hline 13 & 99 & 05 & 2,53 & 44 & 2,53 & & 42 & 2,53 & ,17 & 17 & 09 & & 1,02 & 1,01 & 0,67 & 0,49 & 0,51 & 0,18 & $-0,01$ & $-0,24$ \\
\hline 12 & 2,91 & 83 & 2,35 & 2,28 & 2,34 & 18 & 2,01 & 2,06 & 1,97 & ,63 & 1,55 & 1,48 & 0,79 & 0,67 & 0,60 & 0,43 & 0,49 & 0,12 & $-0,21$ & $-0,27$ \\
\hline 11 & 2,39 & 54 & 2,44 & 2,31 & 2,22 & 12 & 1,93 & 1,97 & 2,22 & 20 & 2,01 & 1,91 & 0,79 & 0,73 & 0,63 & 0,48 & 0,31 & 0,07 & $-0,18$ & $-0,38$ \\
\hline 10 & 2,49 & 55 & 2,45 & 41 & 2,28 & & 01 & 1,97 & & ,40 & 15 & 1,68 & 1,07 & 0,69 & 0,55 & 0,50 & 0,35 & 0,05 & $-0,30$ & $-0,42$ \\
\hline 9 & 2,83 & 2,78 & 2,54 & 2,52 & 2,46 & ,26 & 2,05 & 1,91 & 2,02 & ,21 & 1,81 & 1,57 & 1,37 & 0,69 & 0,56 & 0,51 & 0,22 & 0,04 & $-0,24$ & $-0,40$ \\
\hline 8 & 3,28 & 10 & 2,78 & 2,53 & 2,57 & 2 & 2,23 & 2,03 & 2,01 & 2,05 &, 91 & 1,41 & 1,23 & 0,87 & 0,58 & 0,51 & 0,32 & 0,19 & $-0,41$ & $-0,57$ \\
\hline 7 & 3,45 & 33 & 2,88 & 2,69 & 2,57 & 0 & 2,22 & 1,93 & 1, & 82 & 1,66 & & & 0,85 & 0,63 & 0,64 & 0,38 & 0,32 & $-0,37$ & $-0,51$ \\
\hline 6 & 3,78 & 74 & 3,07 & 2,86 & 2,88 &, 59 & 2,43 & 2,06 & 2,07 & 1,54 & 1,50 & 1,4 & 1,11 & 0,83 & 0,76 & 0,44 & 0,26 & 0,08 & $-0,36$ & $-0,46$ \\
\hline 5 & 4,05 & 80 & 3,40 & 3,13 & 2,93 & 2,76 & 2,54 & 2,49 & 1,99 & 1,81 & 1,83 & 1,57 & 1,12 & 0,87 & 0,75 & 0,33 & $-0,05$ & $-0,05$ & $-0,35$ & $-0,54$ \\
\hline 4 & 4,60 & 20 & 3,75 & 3,18 & 3,18 & 2 & 85 & 2,71 & 2, & 1,99 & 1,89 & 1,85 & 1,23 & 1,01 & 0,91 & 0,10 & $\mid-0,03$ & $-0,14$ & $-0,70$ & $-0,80$ \\
\hline 3 & 4,45 & 4,20 & 4,19 & 3,68 & 3,45 & 3 & 2,90 & 2,69 & 2,42 & 2,09 & 1,93 & 1,77 & 1,51 & 1,34 & 1,18 & $-0,0$ & $-0,16$ & $-0,82$ & $-1,07$ & $-1,01$ \\
\hline 2 & 7,10 & 47 & 4,14 & 3,96 & 3,63 & 40 & 3,34 & 2,91 & 2,75 & 2,43 & 2,08 & 2,05 & 1,66 & 1,19 & 0,73 & $-0,14$ & $-0,29$ & $-1,00$ & $-1,53$ & $-1,95$ \\
\hline 1 & 8,23 &, 58 & 4,26 & 3,98 & 3,36 & 3,06 & 3,89 & 3,07 & 2,90 & 2,50 & 2,16 & 2,34 & 1,72 & 1,03 & 0,50 & $-0,03$ & $-0,19$ & $-1,48$ & $-1,79$ & $-2,64$ \\
\hline & 1 & 2 & 3 & 4 & 5 & 6 & 7 & 8 & 9 & & 11 & 12 & 13 & 14 & 15 & 16 & 17 & 18 & 19 & 20 \\
\hline
\end{tabular}

Figure 2. B2 index distribution on a one-dimensional map.

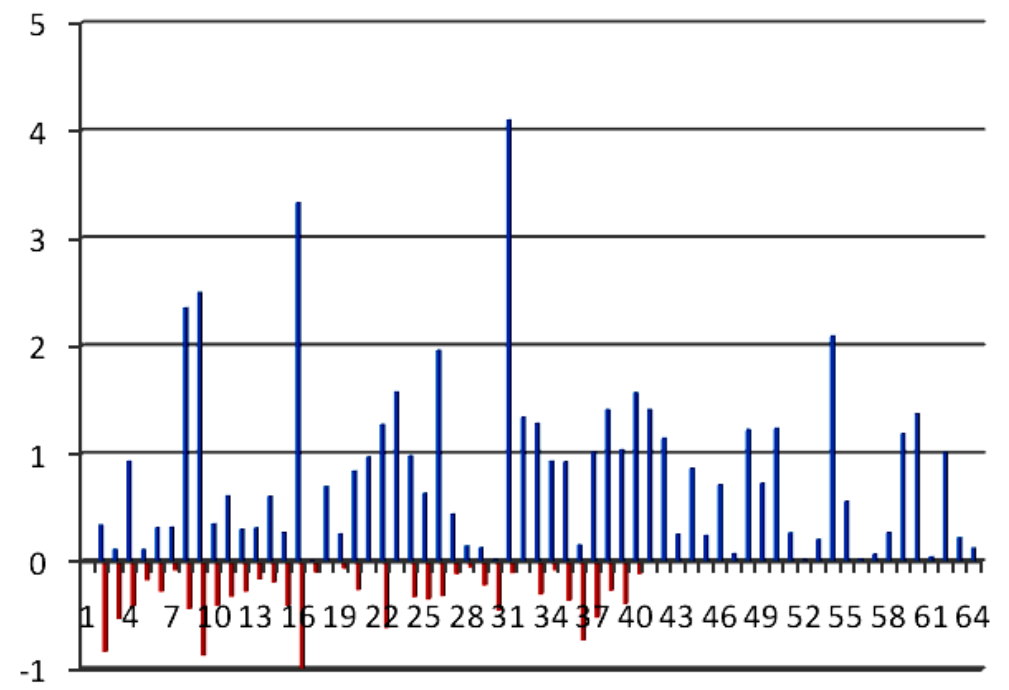

Figure 3. Distribution of the subjects according to the B2 index. There is a clear division between Bipolarism (blue) and MD (red).

The literature also describes how these animals are prone to mood disorders and used for trials of Antidepressant drugs (Table 1 and Figure 3) [44-48].

Delta 6 desaturase remains, however, a problem since platelets don't have this activity [49].

Schick et al. [50-52] who studied the lipid metabolism of Megakaryocytes and platelets, found and underlined that the platelet has a greater quantity of AA and a lower quantity of Oleic Acid (OA) when compared to megakaryocyte.

Why this platelet fatty acids different concentration of AA (main marker of depression) and of OA (main marker of ischemia), as we demonstrate? [25,26]. How is it possible, if the platelet is a bud of the megakaryocyte? It must have the same composition.

Because of the guinea pig position in the SOM map of depression, and since the depressive state was not induced artificially, it was to us very clear that the guinea pig is already depressed at birth. Neither Schick nor nobody else could know this, because they didn't know the SOM map for depression.

We tried to understand from where the metabolic error could come; it was not from the megakaryocyte because it is very unlikely that the platelet gains directly such a specific difference in fatty acid, so we started to think that the error should be at a higher level, probably a 
Table 1. Fatty Acids\% (mean values).

\begin{tabular}{|c|c|c|c|c|c|}
\hline \multicolumn{6}{|c|}{ Fatty Acids\% ( mean values) } \\
\hline & Number of cases & Palmitic Acid & Linoleic Acid & Arachidonic Acid & B2 Index \\
\hline Sheep & 4 pool of 3 & 19.91 & 8.22 & 4.73 & 3.980 \\
\hline Bovine & 4 pool of 3 & 18.37 & 26.72 & 6.77 & 2.937 \\
\hline Cat & 4 pool of 3 & 17.45 & 27.75 & 9.54 & 2.24 \\
\hline Horse & 4 pool of 3 & 14.8 & 23.17 & 6.46 & 2.173 \\
\hline Donkey & 8 pool of 3 & 14.39 & 19.68 & 6.34 & 2.154 \\
\hline Guinea pig & Literature & 17.4 & 12.4 & 14.6 & 1.675 \\
\hline Rat & Literature & 24.4 & 9.5 & 20 & 2.567 \\
\hline Pig & 80 & 26.09 & 8.78 & 14.12 & 3.957 \\
\hline
\end{tabular}

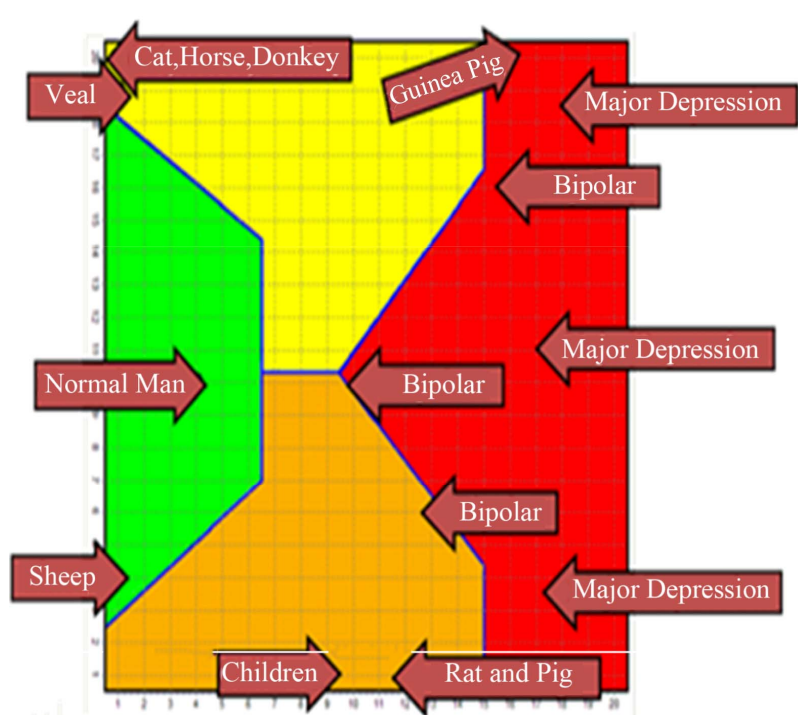

Figure 3. Humans and Animals.

wrong genetic information to platelets regarding the fatty acids concentration, perhaps in the stem cell from which megakaryocytes originate.

Desaturase activity should be involved in some way.

Table 1 and Figure 3 show the average value of the B2 index of the animals investigated and their distribution over the SOM map. Note that horses and donkeys, which belong to the same family, have a very similar index and position in the map. The MD and Bipolar positions correspond respectively to negative and positive index according to Figure 2.

In human subjects, the negative index corresponds to the higher level of arachidonic acid and to a psychiatric diagnosis of MD.

Even in this case the critical point seems to involve the delta 6 desaturase activity, higher than in any other case.

These findings demonstrate that $\mathrm{MD}$ is primarily an expression of human kind and that it belongs to a group of individuals whose biochemical and molecular charac- teristics are completely different from those of any other living being in the human and, perhaps, animal world.

The large number of total cases investigated, the accuracy of matching biochemical and clinical psychiatric diagnoses, the evidence that biochemical evaluation is able to offer a diagnostic accuracy especially when the phenomenon of bipolarity has not yet revealed the psychotic symptom, which is essential for the differential diagnosis from MD, leads to a reflection on the biological meaning of the platelet with respect to the neuron.

Therefore, the questions which arise are:

a) Why platelets are the element that allows us to read a psychiatric disorder?

b) Is, perhaps, in the study of platelet the key that can provide a better molecular understanding of "behavior" and "consciousness"?

However, we do not know, yet, whether anthropology and philosophy can help us or not.

Nevertheless, while we believe that this could be a viable option to make a distinction between MD and Bipolar disorder, we are certainly facing two entirely different models of behavior and consciousness.

\section{Conclusions}

Platelets appear to simulate neurons for the molecular aspects of behavior and consciousness.

The biochemical approach to mental diseases, in the perspective of a biological objectivity which could be the key for clinical diagnosis and phenomenological overviews of depressive and bipolar phenomena, finds in platelets a crucial element to develop a genetic hypothesis on mood and behavior disorders.

The molecular alteration, not only with reference to neurons but also to blood (especially in platelets' cytoskeleton) is closely connected to conscience and, therefore, to behavior. Indeed the membrane Gs $\alpha$ protein and tubulin, whose strands form the microtubules composing cell internal structure, that is to say the cytoskeleton, to- 
gether with membrane viscosity, seem to play a vital role in the mimicking of neurons [34]. The interpretation of platelet molecular phenomena, could allow a better interpretation of consciousness, considering, also, the genetic origin of the psychiatric disease [53].

\section{REFERENCES}

[1] C. A. Evers and L. Starr, "Biology: Concepts and Applications," 6th Edition, Thomson, United States, 2006.

[2] P. J. Marangos, I. C. Campbell, D. E. Schmechel, D. L. Murphy and F. K. Goodwin, "Blood Platelets Contain a Neuron-Specific Enolase Subunit," Journal of Neurochemistry, Vol. 34, No. 5, 1980, pp. 1254-1258. doi:10.1111/j.1471-4159.1980.tb09967.x

[3] B. Leonard, "Clinical Implications of Mechanisms of Action of Antidepressants," Advances in Psychiatric Treatment, Vol. 6, 2000, pp. 178-186. doi:10.1192/apt.6.3.178

[4] J. Olesen, P. J. Goadsby, N. M. Ramadan, P. Tfelt-Hansen and K. M. A. Welch, "The Headaches," 3rd Edition, Lippincott Williams \& Wilkins, Philadelphia, 2006.

[5] S. Takahashi, "Reduction of Blood Platelet Serotonin Levels in Manic and Depressed Patients," Folia Psychiatrica et Neurologica Japonica, Vol. 30, No. 4, 1976, pp. 476-486.

[6] S. M. Stahl, "The Human Platelet. A Diagnostic and Research Tool for the Study of Biogenic Amines in Psychiatric and Neurologic Disorders," Archives of General Psychiatry, Vol. 34, No. 5, 1977, pp. 509-516. doi:10.1001/archpsyc.1977.01770170019001

[7] A. Pletscher and A. Laubscher, "Blood Platelets as Models for Neurons: Uses and Limitations," Journal of Neural Transmission Supplementa, Vol. 16, 1980, pp. 7-16.

[8] M. Da Prada, A. M. Cesura, J. M. Launay and J. G. Richards, "Platelets as a Model for Neurones? Cellular and Molecular Life Sciences, Vol. 44, No. 2, 1988, pp. 115126. doi:10.1007/BF01952193

[9] H. L. Kim, O. Plaisant, M. Leboyer, C. Gay, L. Kamal, M. A. Devynck and P. Meyer, "Reduction of Platelet Serotonin in Major Depression (Endogenous Depression)," $C$ $R$ Seances Acad Sci III, Vol. 295, No. 10, 1982, pp. 619-622.

[10] D. L. Musselman, A. Tomer, A. K. Manatunga, B. T. Knight, M. R. Porter, S. Kasey, U. Marzec, L. A. Harker and C. B. Nemeroff, "Exaggerated Platelet Reactivity in Major Depression," American Journal of Psychiatry, Vol. 153, No. 10, 1996, pp. 1313-1317.

[11] A. Camacho and J. E. Dimsdale, "Platelets and Psychiatry: Lessons Learned from Old and New Studies," Psychosomatic Medicine, Vol. 62, No. 3, 2000, pp. 326-336.

[12] H. Plein and M. Berk, "The Platelet as a Peripheral Marker in Psychiatric Illness," Human Psychopharmacology, Vol. 16, No. 3, 2001, pp. 229-236. doi:10.1002/hup. 251

[13] C.L. Bowden, "Strategies to Reduce Misdiagnosis of Bipolar Depression," Psychiatric Services, Vol. 52, No. 1,
2001, pp. 51-55. doi:10.1176/appi.ps.52.1.51

[14] H. Le-Niculescu, S. M. Kurian, N. Yehyawi, C, Dike, S. D. Patel, H. J. Edenberg, M. T. Tsuang, D. R. Salomon, J. I. Nurnberger and A. B. Niculescu, "Identifying Blood Biomarkers for Mood Disorders Using Convergent Functional Genomics," Molecular Psychiatry, Vol. 14, 2009, pp. 1-19.

[15] I. Hajimohammadreza, M. J. Brammer, S. Eagger, A. Burns and R. Levy, "Platelet and Erythrocyte Membrane Changes in Alzheimer's Disease," Biochimica et Biophysica Acta, Vol. 1025, 1990, pp. 208-214. doi:10.1016/0005-2736(90)90099-A

[16] G. S. Zubenko, B. M. Cohen, C. F. Reynolds, F. Boller, I. Malinakova and N. Keefe, "Platelet Membrane Fluidity in Alzheimer's Disease and Major Depression," American Journal of Psychiatry, Vol. 44, 1987, pp. 860-868.

[17] I. A. Zainaghi, O. V. Forlenza and W. F. Gattaz, “Abnormal APP Processing in Platelets of Patients with Alzheimer's Disease: Correlations with Membrane Fluidity and Cognitive Decline," Psychopharmacology, Vol. 192, No. 4, 2007, pp. 547-553. doi:10.1007/s00213-007-0748-5

[18] M. Giacomini, C. Ruggiero, S. Bertone and L. Calegari, "Artificial Neural Network Identification of Heterotrophic Marine Bacteria Based on Their Fatty-Acid Composition," IEEE Transactions on Biomedical Engineering, Vol. 44, No. 12, 1997, pp. 1185-1191. doi:10.1109/10.649990

[19] P. A. Noble, J. S. Almeida and C. R. Lovell, “Application of Neural Computing Methods for Interpreting Phospholipid Fatty Acid Profiles of Natural Microbial Communities," Applied and Environmental Microbiology, Vol. 66, No. 2, 2000, pp. 694-699.

doi:10.1128/AEM.66.2.694-699.2000

[20] T. Kohonen, "Self Organizing Maps," 3rd Edition, Springer-Verlag, Berlin, 2000.

[21] E. Stachowska, I. Gutowska, B. Dołegowska, D. Chlubek, J. Bober, M. Rać, P. Gutowski, H. Szumilowicz and R. Turowski, "Exchange of Unsaturated Fatty Acids between Adipose Tissue and Atherosclerotic Plaque Studied with Artificial Neural Networks," Prostaglandins Leukot Essent Fatty Acids, Vol. 70, No. 1, 2004, pp. 59-66. doi:10.1016/j.plefa.2003.08.021

[22] E. Stachowska, I. Gutowska, A. Strzelczak, T. Wesołowska, K. Safranow, K. Ciechanowski and D. Chlubek, "The Use of Neural Networks in Evaluation of the Direction and Dynamics of Changes in Lipid Parameters in Kidney Transplant Patients on the Mediterranean Diet," Journal of Renal Nutrition, Vol. 16, No. 2, 2006, pp. 150159. doi:10.1053/j.jrn.2006.01.003

[23] E. Stachowska, I. Gutowska, H. Szumiłowicz, J. Bober and D. Chlubek, "Is Conjugated Linoleic Acid (CLA) a Protective Factor in Atherosclerosis? Study with the Use of Neural Networks," Annales Academiae Medicae Stetinensis, Vol. 51, No. 2, 2005, pp. 27-32.

[24] M. Cocchi, L. Tonello, S. Tsaluchidu and B. K. Puri, "The Use of Artificial Neural Networks to Study Fatty Acids in Neuropsychiatric Disorders," BMC Psychiatry, Vol. 8, Suppl. 1, S3, 2008. 
doi:10.1186/1471-244X-8-S1-S3

[25] M. Cocchi and L. Tonello, "Bio Molecular Considerations in Major Depression and Ischemic Cardiovascular Disease," Central Nervous System Agents in Medicinal Chemistry, Vol. 10, No. 2, 2010, pp. 97-107.

[26] M. Cocchi and L. Tonello, "The Cell Membrane: Is It a Bridge from Psychiatry to Quantum Consciousness?" NeuroQuantology, Vol. 8, No. 1, 2010, pp. 54-60.

[27] D. S. Heron, M. Shinitzky, M. Hershkowitz and D. Samuel, "Lipid Fluidity Markedly Modulates the Binding of Serotonin to Mouse Brain Membranes," Proceedings of the National Academy of Sciences, Vol. 77, 1980, pp. 7463-7467. doi:10.1073/pnas.77.12.7463

[28] R. E. Lee, "Membrane Engineering to Rejuvenate the Ageing Brain," Canadian Medical Association Journal, Vol. 132, 1985, pp. 325-327.

[29] M. Cocchi, L. Tonello, A. De Lucia and P. Amato, "Platelet and Brain Fatty Acids: A Model for the Classification of the Animals? Part 1," International Journal of Anthropology, Vol. 24, No. 1, 2009, pp. 69-76.

[30] M. Cocchi, L. Tonello, A. De Lucia and P. Amato, "Platelet and Brain Fatty Acids: a Model for the Classification of the Animals? Part 2. Platelet and Brain Fatty Acid Transfer: Hypothesis on Arachidonic Acid and its relationship to Major Depression," International Journal of Anthropology, Vol. 24, No. 3, 2009, pp. 201-220.

[31] P. Green, I. Gispan-Herman and G. Yadid, "Increased Arachidonic Acid Concentration in the Brain of Flinders Sensitive Line Rats, an Animal Model of Epression," Journal of Lipid Research, Vol. 46, 2005, pp. 1093-1096. doi:10.1194/jlr.C500003-JLR200

[32] H. Tiemeier, H. R. Tuijl, A. Hofman, A. J. Kiliaan and M. M. B. Breteler, "Plasma Fatty Acid Composition and depression Are Associated in the Elderly: The Rotterdam Study 1," American Journal of Clinical Nutrition, Vol. 78, 2003, pp. 40-46.

[33] M. Cocchi, F. Gabrielli, L. Tonello and M. Pregnolato, "The Interactome Hypothesis of Depression," NeuroQuantology, Vol. 4, 2010, pp. 603-613.

[34] M. Cocchi, L. Tonello and G. Lercker, "Fatty Acids, Membrane Viscosity, Serotonin and Ischemic Heart Disease," Lipids in Health and Disease, Vol. 9, 2010, p. 97. doi:10.1186/1476-511X-9-97

[35] M. Cocchi, L. Tonello, F. Gabrielli and M. Pregnolato, "Biological and Anthropological-Existential Hypothesis on Depression," Quantum Biosystems, Vol. 3, No. 1, 2011, pp. 12-18.

[36] M. Cocchi, L. Tonello, F. Gabrielli, M. Pregnolato and E. Pessa, "Quantum Human \& Animal Consciousness: A Concept Embracing Philosophy, Quantitative Molecular Biology \& Mathematics," Journal of Consciousness Exploration \& Research, Vol. 2, 2011, pp. 547-574.

[37] M. Cocchi, F. Gabrielli, L. Tonello and M. Pregnolato, "Consciousness and Hallucinations: Molecular Considerations and Theoretical Questions," NeuroQuantology, Vol. 9, 2011, pp. 182-189.

[38] M. Cocchi, F. Gabrielli, L. Tonello and M. Pregnolato, "Depression, Osteoporosis, Serotonin and Cell Membrane
Viscosity between Biology and Philosophical Anthropology," Annals of General Psychiatry, Vol. 10, 2011, p. 9. doi:10.1186/1744-859X-10-9

[39] M. Cocchi, L. Sardi, L. Tonello and G. Martelli, "Do Mood Disorders Play a Role on Pig Welfare?" Italian Journal of Animal Science, Vol. 8, 2009, pp. 691-704.

[40] M. Cocchi, L. Tonello and F. Gabrielli, "The Animal Side of Mood Disorders," Lambert Academic Publishing, Saarbrücken, 2001.

[41] G. J. Nelson, P. C. Schmidt, G. Bartolini, D. S. Kelley and D. Kyle, "The Effect of Dietary Arachidonic Acid on Platelet Function, Platelet Fatty Acid Composition, and Blood Coagulation in Humans," Lipids, Vol. 32, No. 4, 1997, 421-425. doi:10.1007/s11745-997-0055-7

[42] R. Pamplona, G. Barja and M. Portero-Otín, "Membrane Fatty Acid Unsaturation, Protection against Oxidative Stress, and Maximum Life Span," Annals of the New York Academy of Sciences, Vol. 959, 2006, pp. 475-490. doi:10.1111/j.1749-6632.2002.tb02118.x

[43] C. L. Quilter, C. L. Gilbert, G. L. Oliver, O. Jafer, R. A. Furlong, S. C. Blott, A. E. Wilson, C. A. Sargent, A. Mileham and N. A. Affara, "A Model for Puerperal Psychosis," American Journal of Medical Genetics, Part B, Vol. 147B, 2008, pp. 1126-1137. doi:10.1002/ajmg.b.30734

[44] A. Rex, J. P. Voigt, K. M. Wicke and H. Fink, "In Vivo/ex Vivo and Behavioural Study on Central Effects of 5-HT1B/1D and 5-HT1A Antagonists in Guinea Pigs," Pharmacology Biochemistry \& Behavior, Vol. 88, No. 3, 2008, pp. 196-204. doi:10.1016/j.pbb.2007.07.016

[45] D. H. Overstreet, J. Stemmelin and G. Griebel, "Confirmation of Antidepressant Potential of the Selective Beta3 Adrenoceptor Agonist Amibegron in an Animal Model of Depression," Pharmacology Biochemistry \& Behavior, Vol. 89, No. 4, 2008, pp. 623-626.

doi:10.1016/j.pbb.2008.02.020

[46] D. Owen and S. G. Matthews, "Repeated Maternal Glico Corticoid Treatment Affects Activity and Hippocampal NMDA Receptor Expression in Juvenile Guinea Pigs," Physiology, Vol. 578, No. 1, 2007, pp. 249-257. doi:10.1113/jphysiol.2006.122887

[47] C. Belzung and G. Griebel, "Measuring Normal and Pathological Anxiety-Like Behaviour in Mice: A Review," Behavioural Brain Research, Vol. 125, 2001, pp. 141-140. doi:10.1016/S0166-4328(01)00291-1

[48] G. Griebel, "5-Hydroxytryptamine-Interacting Drugs in Animal Models of Anxiety Disorders: More than 30 Years of Research," Pharmacology \& Therapeutics, Vol. 65, 1995, pp. 319-395. doi:10.1016/0163-7258(95)98597-J

[49] M. Boberg, L. B. Croon, I. B. Gustafsson and B. Vessby, "Platelet Fatty Acid Composition in Relation to Fatty Acid Composition in Plasma and to Serum Lipoprotein Lipids in Healthy Subjects with Special Reference to the linoleic acid pathway," Clinical Science, Vol. 68, No. 5, 1985, pp. 581-587.

[50] P. K. Schick and X. L. He, "Composition and Synthesis of Glycolipids in Megakaryocytes and Platelets: Differ- 
ences in Synthesis in Megakaryocytes at Different Stages of Maturation," Journal of Lipid Research, Vol. 31, 1990, pp. $1645-1654$.

[51] B. P. Schick and P. K. Schick, "Lipid Composition of Guinea Pig Platelets and Megakaryocytes. The Megakaryocyte as a Probable Source of Platelet Lipids," Biochimica et Biophysica Acta, Vol. 663, 1981, pp. 239-248.

[52] P. K. Schick, K. Williams-Gartner and X. L. He, "Lipid
Composition and Metabolism in Megakaryocytes at Different Stages of Maturation," Journal of Lipid Research, Vol. 31, 1990, pp. 27-35.

[53] K. Karg, M. Burmeister, K. Shedden and S. Sen, "The Serotonin Transporter Promoter Variant (5-HTTLPR), Stress, and Depression Meta-analysis Revisited," Arch Gen Psychiatry, Vol. 68, 2011, pp. 444-454. doi:10.1001/archgenpsychiatry.2010.189 